\title{
UNDERSTANDING THE OXIDE DISPERSION BEHAVIOR OF YTTRIA IN METAL MATRIX OF MA956 ALLOY THROUGH HIGH-ENERGY MILLING AND HOT PRESS SINTERING
}

\begin{abstract}
MA956 (Fe-Cr-Al) alloy powder was high-energy ball milled with various amount of yttria contents (1,2,3, and 4 wt.\%) to fabricate an oxide dispersion strengthened alloy. The milled powders were then consolidated using hot press sintering at $1150^{\circ} \mathrm{C}$. The surface morphology and crystal structure of MA956 powder during the high-energy milling depending on the yttria contents was investigated using particle size analysis, X-ray diffraction, and scanning electron microscopy. The microstructural analysis of sintered alloy was performed using transmission electron microscopy and energy dispersive spectroscopy to evaluate the dispersion behavior of yttrium oxide. The results showed that, as yttria contents increased, the oxide particles became finer and are uniformly distributed during the high-energy milling. However, after the sintering, the oxide particles were coarsened with more than 3 wt. $\%$ of yttria addition.

Keywords: ODS, mechanical alloying, high-energy milling, oxide particle distribution
\end{abstract}

\section{Introduction}

Generation IV (Gen-IV) high-temperature gas-cooled reactor (HTGR) or very-high-temperature reactor (VHTR) requires new structural materials to be operated beyond $500^{\circ} \mathrm{C}$ [1-3]. The primary challenge for Gen-IV HTGR is the performance and reliability of structural materials for both inner-core and outercore applications at the operation temperature of about $1000^{\circ} \mathrm{C}$ [1-3]. Intensive irradiation of high-energy neutrons (14 MeV) significantly corrodes and damages the reactor $[3,4]$. Therefore, the development of reliable structural materials against high temperature, strong neutron irradiation, and extremely corrosive environment is essential for the application of the inner/outer core of Gen-IV HTGR. Nanostructured ferritic oxide dispersion strengthened (ODS) alloy is a promising candidate for these applications. Ferritic ODS alloy reportedly exhibits good resistance to radiation-induced swelling and oxidation/corrosion at elevated temperatures [4]. The mechanical properties of ferritic ODS alloy can be further improved by the modification of dislocation density or grain boundaries [9,10].

Mechanical alloying (MA) is a well-known technique used in order to distribute oxide particles uniformly in the metal matrix preventing the aggregation of oxide particles which is commonly occurred during conventional casting process due to the low solubility of the oxides of metals [11]. The MA of steel powders with yttria $\left(\mathrm{Y}_{2} \mathrm{O}_{3}\right)$ particles successfully fabricated nanostruc- tured ferritic ODS alloy $[9,12]$, and the microstructural evolution of yttria particles in ODS steel during MA was investigated $[9,10,13]$. Also, the radiation stability [14], high-temperature mechanical properties $[15,16]$, applications to reactor [17-19] of ODS ferritic steels with yttria have been reported.

In the present research, the dispersion behavior of yttria in metal matrix of MA956 alloy depending on the contents of yttria during high-energy ball milling has been investigated in detail.

\section{Experimental (Material and Methods)}

MA956 powder (Fe-Cr-Al) with average size of $58 \mu \mathrm{m}$ and yttria $\left(\mathrm{Y}_{2} \mathrm{O}_{3}\right)$ particles with average size of $40 \sim 60 \mathrm{~nm}$ were used for MA via high-energy planetary ball mill (TMHP-500, $\mathrm{KMTECH}$ ). The yttria particles were added in four different compositions $(1,2,3$, and 4 wt.\%) and compared with milled condition without yttria and unmilled MA956 alloy. The highenergy milling was conducted using $500 \mathrm{ml}$ vessels at $600 \mathrm{rpm}$. The stainless steel ball was used in the bimodal sizes of 2 and $3 \mathrm{~mm}$ with a ball-to-powder ratio (BPR) of 10:1. In order to prevent undesired oxidation on the powder surface, all powder handlings were performed inside a glove box with Ar atmosphere. The milled powders were subsequently sintered using a vacuum hot press at $1150^{\circ} \mathrm{C}, 50 \mathrm{MPa}$, and $3.3 \times 10^{-2}$ torr. The composition of MA956 powder was analyzed by XRF (XRF-

\footnotetext{
* ADVANCED MATERIALS \& PROCESSING CENTER, INSTITUTE FOR ADVANCED ENGINEERING, YOUNGIN, KOREA

** DEPARTMENT OF MATERIALS SCIENCE AND ENGINEERING \& ENERGY SYSTEMS RESEARCH, AJOU UNIVERSITY, 206 WORLDCUP-RO, YEONGTONG-GU, SUWON, GYEONGGI, 16499, KOREA

THESE AUTHORS CONTRIBUTED EQUALLY TO THIS WORK.

Corresponding author: byungmin@ajou.ac.kr
} 
1800, SHIMADZU). The particle size distribution was analyzed using a PSA (Bluewave S3500, MICROTRAC), and the oxide dispersion was investigated using an XRD (XRD-6100, SHIMADZU). The microstructural characterization was performed in each step of processes using an SEM (JSM-6700F, JEOL) and a TEM (Tecnai G2, FEI).

\section{Results and discussion}

Table 1 shows the elemental composition of MA956 powder. Mechanical milling of MA956 powders with yttria was carried out adding different wt.\% of yttria. From 0 to 4 wt.\% of yttria powder was mechanically milled with MA956 powder and compared with unprocessed (bare) MA956 powder. Fig. 1a shows the average particle size $\left(\mathrm{D}_{50}\right)$ and Fig. $1 \mathrm{~b}$ shows the volume fraction of powder as a function of different wt. $\%$ of yttria. Fig. 1a shows that the particle size of MA956 was decreased from 58.91 to $10.80 \mu \mathrm{m}$. When $1 \mathrm{wt} . \%$ yttria powder was mechanically milled with MA956 powder, the particle size remained almost the same. As the yttria contents increased from $2-4$ wt. $\%$, the particle size gradually decreased from 11.49 to $4.92 \mu \mathrm{m}$. Fig. 1b shows that, when higher wt.\% of yttria, not only the particle decreased, but also the volume fraction of smaller particle size also increased. Up to $2 \mathrm{wt} . \%$ addition of $y$ ttria, the fine oxides are rapidly attached on the surface of powder through the flattening of the mechanical milling process. With more than $2 \mathrm{wt} . \%$ addition of yttria, the fine oxides attachment become less significant on the flattened surface of the powder. Therefore, the apparent change in the particle size was relatively small. At 3 wt. $\%$ addition of yttria, the oxide particles were stuck to the flattened surface up to several tens of nanometers in size which makes more difficult for further size reduction. The oxide sticking to the flattened surface reduces interfacial energy which promotes cold welding effects. It was reported that lower interfacial energy promotes cold welding as a result that oxides sticking over a flattened surface resists further size reduction in mechanical milling in spite of higher contents of yttria [20].

TABLE 1

Composition of MA956 powder

\begin{tabular}{|c|c|c|c|c|c|c|}
\hline \hline Elements & Fe & Cr & Al & Ti & Y & Ni \\
\hline Wt. \% & 74.78 & 18.70 & 5.60 & 0.63 & 0.22 & 0.07 \\
\hline
\end{tabular}

Fig. 2 shows a comparison of XRD pattern of the unmilled sample and mechanically milled sample using various contents of yttria. It shows, the Fe peak distinctly appears in the bare MA956 powder, whereas the same Fe peak of yttria added and milled powders was broadened, and has lower intensities. Similarly, the bare sample has a distinct peak of $\mathrm{Y}_{2} \mathrm{O}_{3}$ peak at $2 \theta=29.20^{\circ}$. However, the oxide peak of yttria added and high energy mechanically milled powders sample was fully disappeared. Thus oxide was completely dispersed in the Fe matrix.
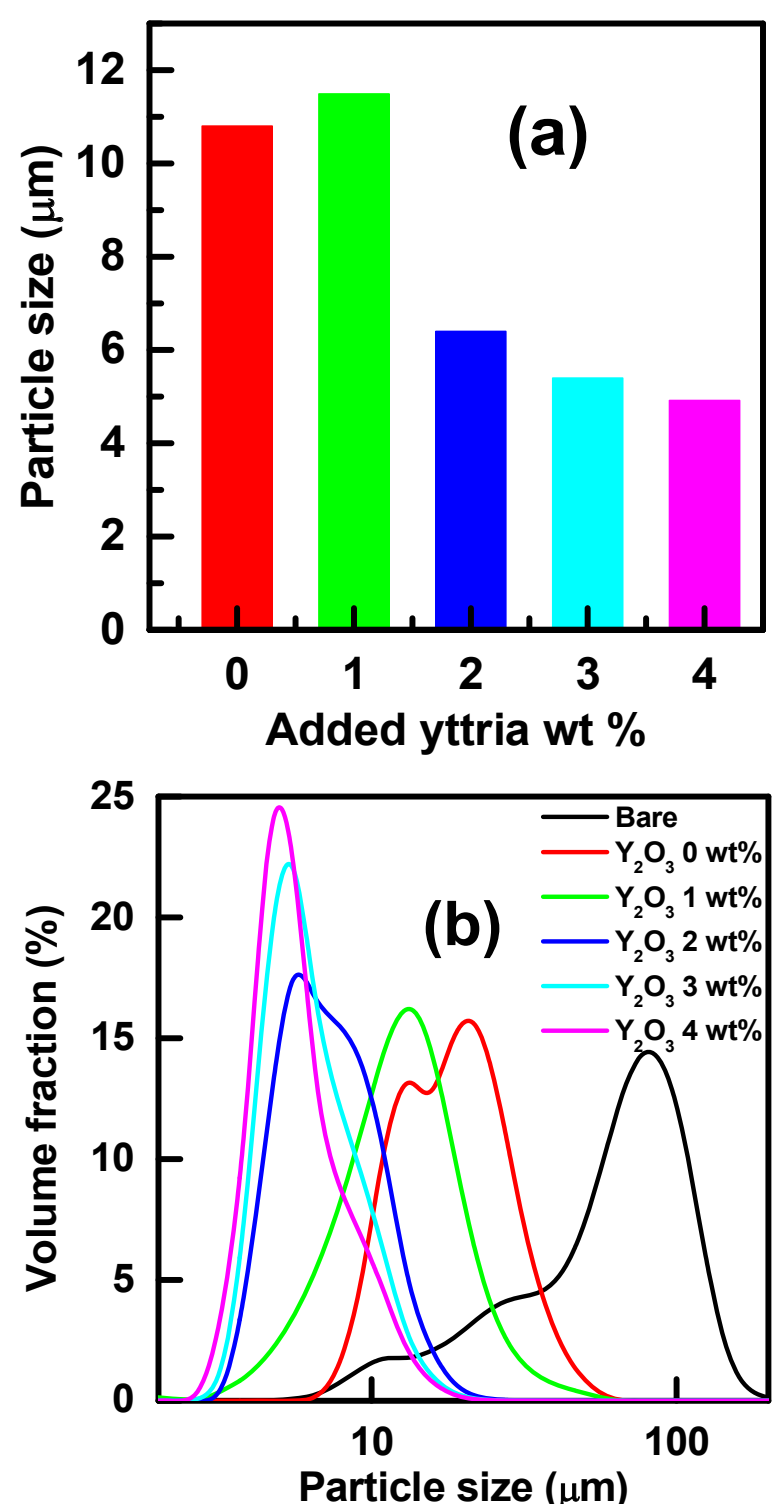

Fig. 1. Powder size distribution after mechanical milling: (a) powder size (D50) and (b) Size distribution

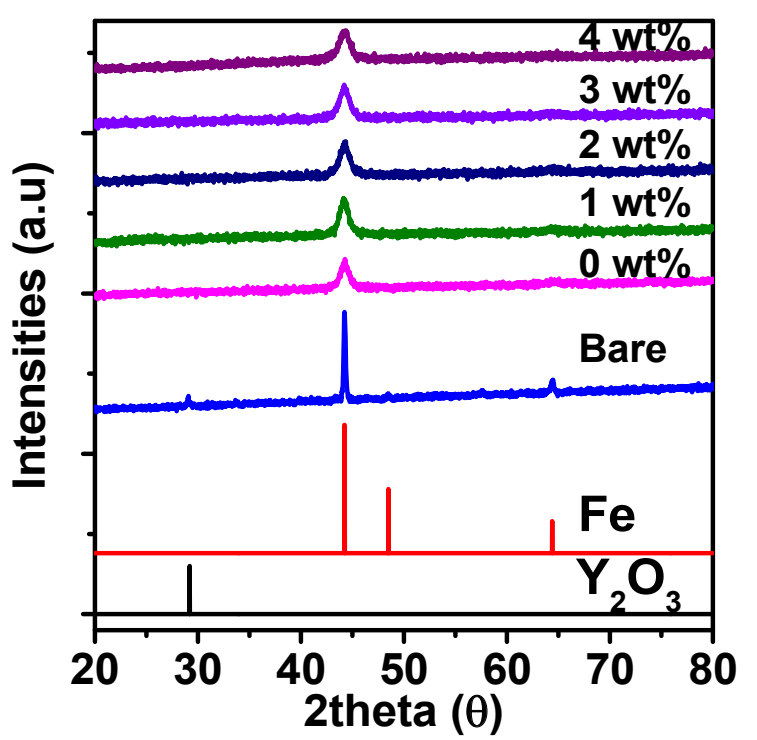

Fig. 2. XRD pattern of high-energy ball milled MA956 powder using various wt. $\%$ of $\mathrm{Y}_{2} \mathrm{O}_{3}$, bare sample and references of $\mathrm{Fe}$ and $\mathrm{Y}_{2} \mathrm{O}_{3}$ 
As explained elsewhere $\mathrm{Y}_{2} \mathrm{O}_{3}$ oxide was completely decomposed into the metal matrix of MA956 alloy [3,21].

Fig. 3 shows SEM of bare and high energy mechanical milled samples. Fig. 3a-f shows the morphology of bare MA956 powder, only milled MA956 powder, 1 wt.\%, 2 wt.\%, 3 wt.\%, and $4 \mathrm{wt} . \%$ yttria added samples, respectively. The Fig. 3 shows the bare MA956 powder was completely spherical, whence, after milling powder has undergone sufficient plastic deformation which flattened and dispersed oxide over the metal matrix. The flattened powders were agglomeration in the irregular spherical pattern. Gradual size reduction and apparent similarities in irregular spherical is limiting to a steady state (Fig. 3d-f). As explained by Benjamin et al. after sufficient plastic deformation and cold welding the particle size of powder reached a steadystate[22].
Figs. 1,2 and 3 express beyond 2 wt.\% yttria addition condition have reached the sufficient plastic deformation and cold welding, hence, the particle size of powder reached a steadystate. Selectively 1,2 and 4 wt.\% yttria added and high energy mechanically milled powder was sintered by the hot press as explained in the experimental procedure explained in the experimental section. TEM-EDS of each hot pressed sintered sample was analyzed. Fig. 4a,b shows TEM-EDS of sintered powder of $1 \mathrm{wt} . \%$ and $2 \mathrm{wt} . \%$, respectively. The EDS shows that the oxides are distributed in metal (Al) matrix. The same EDS figure also shows $\mathrm{Y}_{2} \mathrm{O}_{3}$ was diffused to the $\mathrm{Al}$ matrix of MA956 and formed Al-Y-O oxide, which is the contributing cause of the disappearance of yttria peak in XRD pattern of yttria added and mechanically milled sample. The same kind of phenomenon also reported by Hsiung et al. [4].
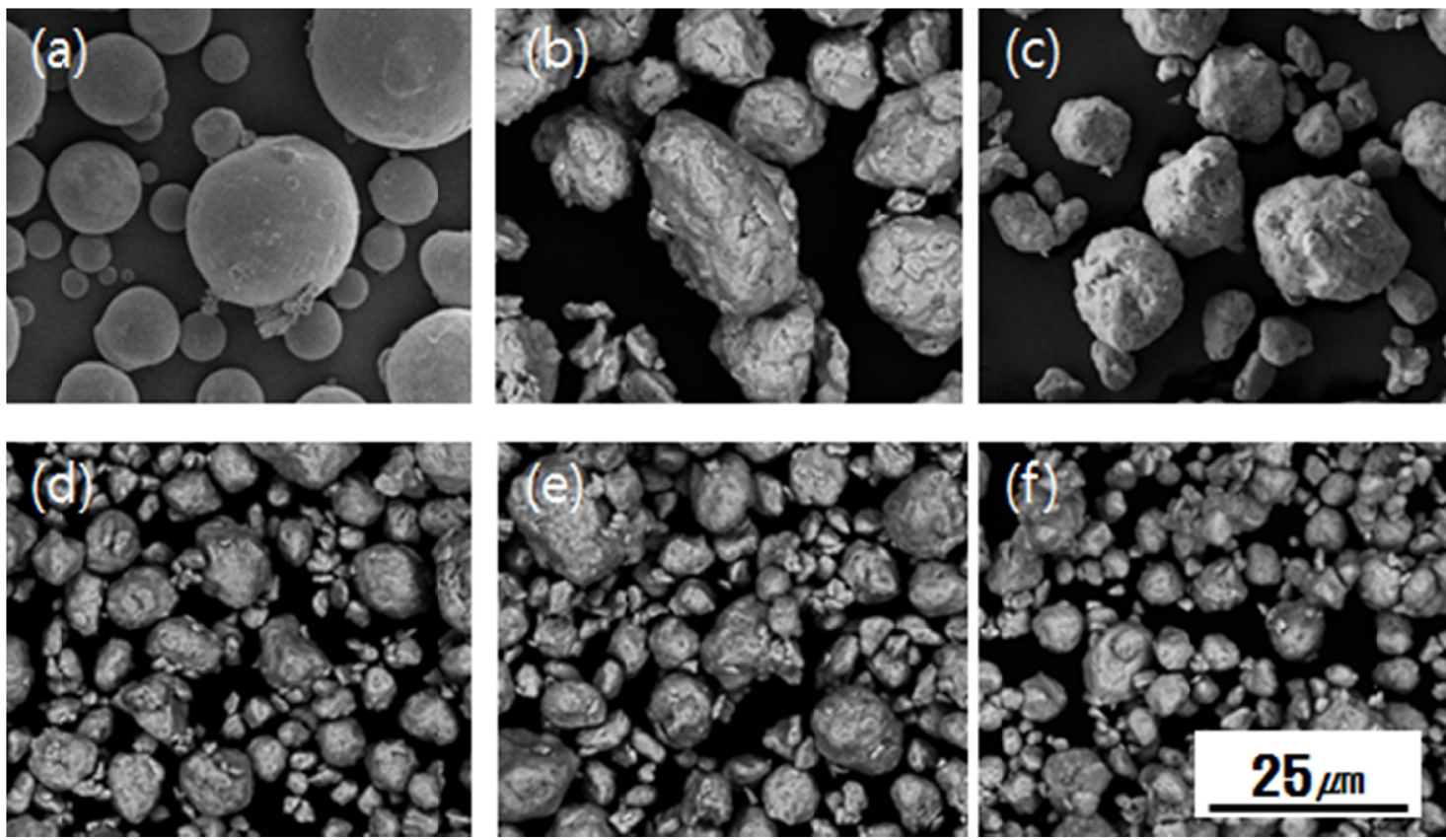

Fig. 3. SEM images of (a) MA956 powder (bare sample), (b-f) high-energy ball milled powder with addition of $0,1,2,3$ and 4 wt. \% $\mathrm{Y}_{2} \mathrm{O}_{3}$

Oxide distribution and oxide size distributions were analyzed from TEM images. TEM in Fig. 5a-c identifies the Al-Y-O sites for 1,2 and 4 wt.\% yttria added mechanically alloyed samples, respectively. Fig. 5 clearly indicates that, with increasing added yttria in the alloyed MA956 samples, the size of Al-Y-O size gradually decreases. The size distribution of oxides of the yttria sintered samples is shown in Fig. 6, which were analyzed form from TEM image of Fig. 5. The Fig. 6 shows, in the case of 1 wt. $\%$ added yttria sintered MA956 alloy forms Al-Y-O inside the metal matrix, approximate size of 10 20 nm. At adding more than $2 \mathrm{wt} \%$ yttria, Al-Y-O particle is formed about $100 \mathrm{~nm}$ size during sintering process. Thus, sufficient dispersion of yttria powder which ultimately forms Al-Y-O particle was confirmed by the TEM-EDS, XRD, PSA, SEM analysis. The size of dispersed oxide is important in ODS alloy to determine its properties. In the case of very coarse particles critically unfavorable for ODS alloy, because enormous oxide resist the movement of the dislocation, which concentrates the stress, subsequently stress concentration generate crack. By the reason, the reduce of oxide particle size is important to fabrication of ODS alloys. Hence, the dispersed oxide as Al-Y-O particle inside the metal matrix of $100 \mathrm{~nm}$ size or less was considered as the optimum condition for ODS alloy [5].

\section{Conclusions}

This investigation confirmed that yttria particles were finely dispersed in the metal matrix of MA956 alloy through mechanical milling followed by hot press at $1150^{\circ} \mathrm{C}$. With the addition of 2-3 wt.\% yttria to MA956 through MA, the oxide dispersion was improved. When the contents of yttria addition increased, the fine oxide particles were decreased because of cold welding effect, shielding the metal surface through the 


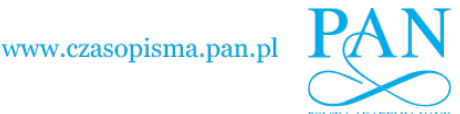

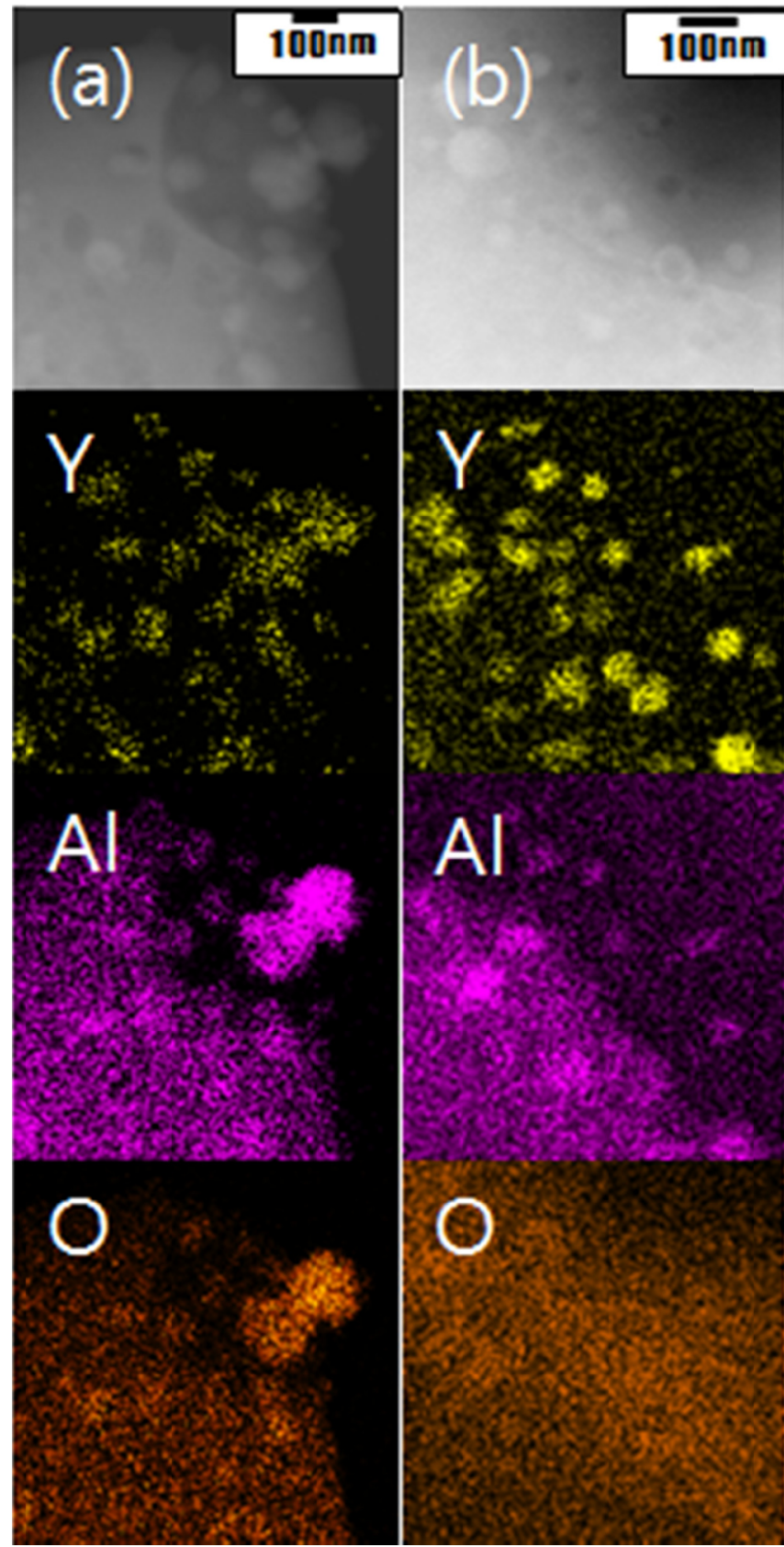

Fig. 4. EDS spectra for oxide dispersion of milled MA956 sample with the addition of (a) 1 wt.\%, (b) 2 wt. $\% \mathrm{Y}_{2} \mathrm{O}_{3}$

flattening surface during MA, and there was minimal or no significant change in oxide dispersion behavior was observed. Higher density of fine dispersion particles behaves barriers for dislocation movement. Therefore, the MA with $3 \mathrm{wt} . \%$ yttria addition provides a potential for ODS ferritic MA956 alloy to high-temperature applications by the modification of dispersion behavior of oxide particles.

\section{Acknowledgments}

This research was supported by the Regional Technology Innovation Program (grant no. 100448458) of the Ministry of Trade, Industry, and Energy (MOTIE), Republic of Korea.
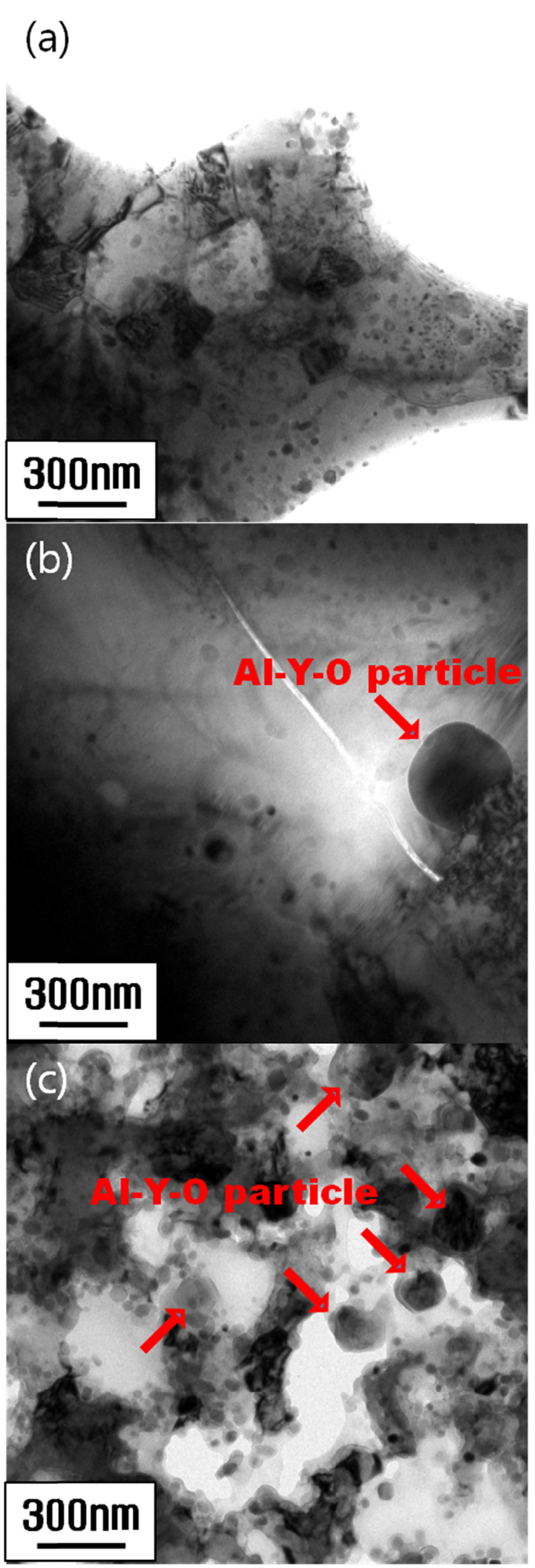

Fig. 5. TEM image reflecting the oxide size of the yttria sintered MA956 sample with the addition of (a) 1 wt.\%, (b) 2 wt.\% $\mathrm{Y}_{2} \mathrm{O}_{3}$ 

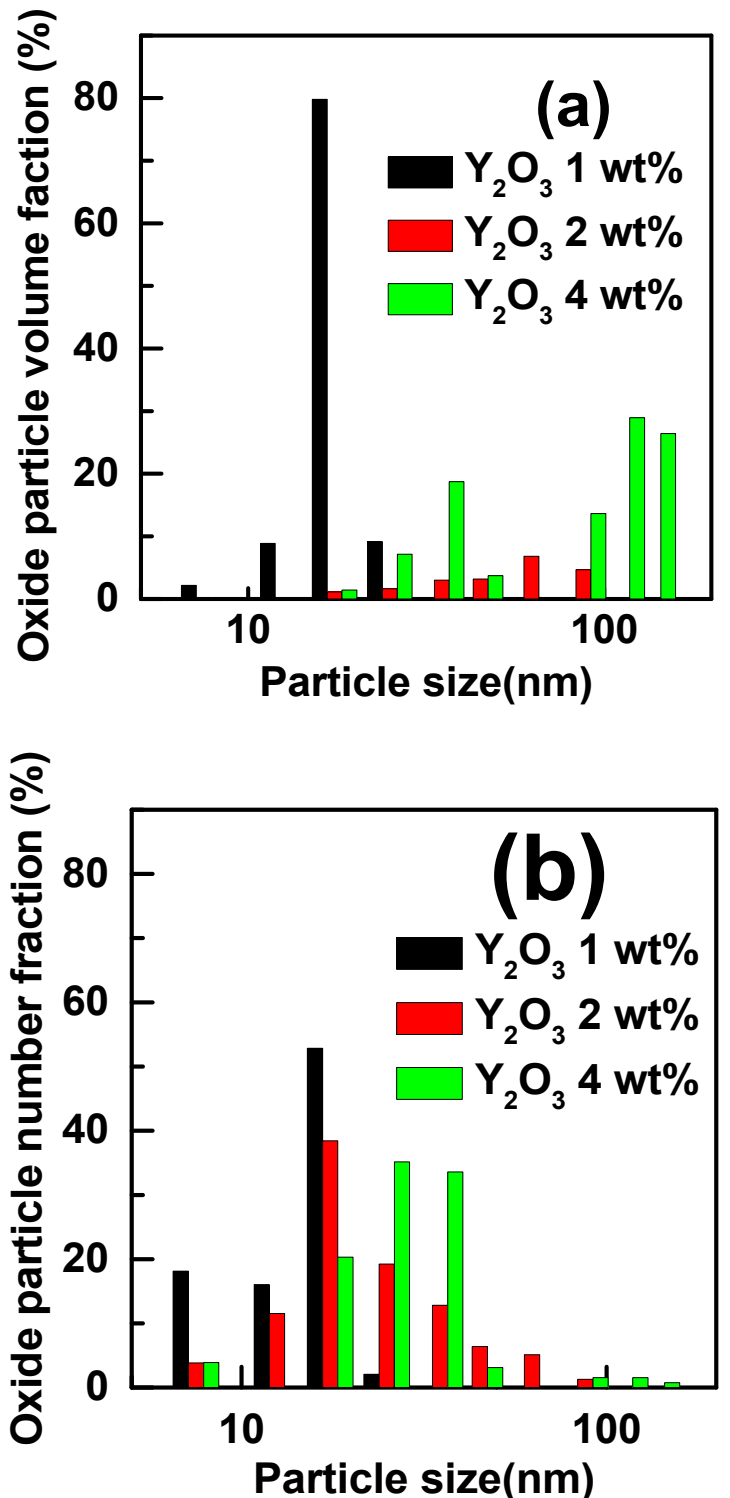

Fig. 6. Size distribution of the oxides: (a) volume fraction, (b) oxide particle fraction after MA of MA956 with 1, 2 and 4 wt.\% of $\mathrm{Y}_{2} \mathrm{O}_{3}$

\section{REFERENCES}

[1] L.K. Mansur, A.F. Rowcliffe, R.K. Nanstad, S.J. Zinkle, W.R. Corwin, R.E. Stoller, Materials needs for fusion, Journal of Nuclear Materials Part A 166-172, 329-333 (2004).

[2] K.L. Murty, I. Charit, Journal of Nuclear Materials 383, 189-195 (2008).
[3] H. Xu, Z. Lu, D. Wang, C. Liu, Nuclear Materials and Energy 7, $1-4$ (2016).

[4] L.L. Hsiung, M.J. Fluss, S.J. Tumey, B.W. Choi, Y. Serruys, F. Willaime, A. Kimura, Physical Review B, 82, 184103 (2010).

[5] R.L. Klueh, J.P. Shingledecker, R.W. Swindeman, D.T. Hoelzer, Journal of Nuclear Materials 341, 103-114 (2005).

[6] S. Ohtsuka, S. Ukai, M. Fujiwara, Journal of Nuclear Materials 351, 241-246 (2006).

[7] T. Kaito, S. Ohtsuka, M. Inoue, T. Asayama, T. Uwaba, S. Mizuta, S. Ukai, T. Furukawa, C. Ito, E. Kagota, R. Kitamura, T. Aoyama, T. Ioue, Journal of Nuclear Materials 386-388, 294-298 (2009).

[8] T. Allen, J. Busby, M. Meyer, D. Petti, Materials Today 13, 14-23 (2010).

[9] L. Dai, Y. Liu, Z. Dong, Powder Technology 217, 281-287 (2012).

[10] N.Y. Iwata, R. Kasada, A. Kimura, T. Okuda, M. Inoue, F. Abe, S. Ukai, S. Ohnuki, T. Fujisawa, ISIJ International 49, 1914-1919 (2009).

[11] H. Sakasegawa, M. Tamura, S. Ohtsuka, S. Ukai, H. Tanigawa, A. Kohyama, M. Fujiwara, Journal of Alloys and Compounds 452, 2-6 (2008).

[12] Z. Oksiuta, N. Baluc, Journal of Nuclear Materials 374, 178-184 (2008).

[13] T. Liu, H. Shen, C. Wang, W. Chou, Progress in Natural Science: Materials International 23, 434-439 (2013).

[14] I. Monnet, P. Dubuisson, Y. Serruys, M.O. Ruault, O. Ka1"tasov, B. Jouffrey, Journal of Nuclear Materials 335, 311-321 (2004).

[15] R.L. Klueh, P.J. Maziasz, I.S. Kim, L. Heatherly, D.T. Hoelzer, N. Hashimoto, E.A. Kenik, K. Miyahara, Journal of Nuclear Materials Part 1 307-311, 773-777 (2002).

[16] D.K. Mukhopadhyay, F.H. Froes, D.S. Gelles, Journal of Nuclear Materials Part 2 258-263, 1209-1215 (1998).

[17] S. Ukai, T. Nishida, H. Okada, T. Okuda, M. Fujiwara, K. Asabe, Journal of Nuclear Science and Technology 34, 256-263 (1997).

[18] S. Ukai, T. Nishida, T. Okuda, T. Yoshitake, Journal of Nuclear Science and Technology 35, 294-300 (1998).

[19] S. Ukai, S. Mizuta, T. Yoshitake, T. Okuda, M. Fujiwara, S. Hagi, T. Kobayashi, Journal of Nuclear Materials Part 1 283-287, 702706 (2000).

[20] C. Suryanarayana, Progress in Materials Science 46, 1-184 (2001).

[21] Z. Oksiuta, Acta Mechanica et Automatica, The Journal of Bialystok Technical University 5, 74-78 (2011).

[22] J.S. Benjamin, T.E. Volin, Metallurgical Transactions 5, 1929-1934 (1974). 